\title{
Application of Hydrothermal Treatment on BF Slag and Waste Glass for Preparing Lubricant Materials in High Strain Rolling for Ultrafine-grained Steel Production
}

\author{
Shinsuke SATO, ${ }^{1)}$ Takeshi YOSHIKAWA, ${ }^{1)}$ Masashi NAKAMOTO, ${ }^{2)}$ Toshihiro TANAKA ${ }^{1)}$ and Jiro IKEDA ${ }^{3)}$ \\ 1) Division of Materials and Manufacturing Science, Osaka University, 2-1 Yamadaoka, Suita, Osaka 565-0871 Japan. \\ 2) Graduate School of Engineering, Osaka University, 2-1 Yamadaoka, Suita, Osaka 565-0871 Japan. \\ 3) Technical Research Laboratory, Daido-chemical Industry Co. Ltd., 1021 Kitamachi Nukata-gun, Yamatokoriyama, Nara 639- \\ 1037 Japan
}

(Received on October 5, 2007; accepted on November 22, 2007)

\begin{abstract}
In order to establish a high strain rolling process for the production of ultrafine-grained steels, a new lubricant showing stable biting between rolls and workpieces as well as a lubricating effect inside the hot rolls is required. We focused on glass materials for the stable biting property in view of their hardness and investigated the possibility of applying blast furnace (BF) slag and waste glass as the lubricant. The addition of a lubricating property to these glass materials was attempted by water introduction with a hydrothermal treatment, using the water release with heating that leads to a structural change inside the hot rolls. For that purpose, the hydrothermal treatment of the BF slag and waste glass was carried out, and the water release with re-heating was investigated. Furthermore, friction properties of the synthesized lubricants containing the hydrothermally treated materials were measured by a Timken extreme pressure tester at 373-1 $173 \mathrm{~K}$.
\end{abstract}

KEY WORDS: blast furnace slag; waste glass; hydrothermal reaction; lubricant; water release; friction coefficient.

\section{Introduction}

Blast furnace slag is generated in large quantities, i.e. 24.8 billion tonnes per year in Japan in 2006. ${ }^{1)}$ Although most has been recycled as raw materials of roadbeds and cements, new processes for producing value-added materials are demanded. Since this slag consists of major components of ceramic materials such as $\mathrm{SiO}_{2}, \mathrm{CaO}, \mathrm{Al}_{2} \mathrm{O}_{3}$, and $\mathrm{MgO}$, high temperature treatments are generally applied in the recycling to produce functional ceramics. When energy consumption and $\mathrm{CO}_{2}$ emission are considered, however, such high temperature processes may not be feasible for the slag treatment. Therefore, the authors have focused on the application of hydrothermal reactions to the slag, aiming at the production of functional ceramics. Hydrothermal reactions are operated in a temperature range of $423-623 \mathrm{~K}$, which can be controlled using the exhausted heat from the iron and steel making processes. The application of the hydrothermal reactions is one of the promising environmentally friendly processes to cope with slag recycling issues in the iron and steel making industry as discussed by Hashida. ${ }^{2)}$ Waste glass is also expected to be re-used in valuable materials, and is known for its high reactivity during the hydrothermal process. ${ }^{3)}$

On the other hand, development of the production process for ultrafine-grained steels has been attempted. ${ }^{4}$ High strain rolling is one of the key technologies for continuous pro- duction. ${ }^{5)}$ The fabrication of new lubricants is required in the process, which would allow the stable biting between rolls and workpieces under a heavy load and a lubricating effect in the hot rolls. When glass material is applied as a lubricant, it can be expected to give a suitable biting property in view of its hardness. Hence, we focused on the application of water-cooled BF slag mainly possessing a glass structure and waste glass. The use of the slag as a lubricant is also advantageous in constructing the in-house material reuse process in the iron and steel-making plant. Both glass materials, however, are not expected to show lubricity when charged into hot rolls because they do not have fluidity at an inside temperature of hot rolls since their melting temperatures are usually much higher.

Henceforth, the authors have focused on the hydrothermal treatment of glass materials to improve the heating behavior by introducing water. By the hydrothermal treatment of sodium-silicate based glass, it was clarified that a large water content of glass leads to a low temperature glass transition. $\left.{ }^{6}\right)$ Furthermore, the hydrothermally treated $\mathrm{SiO}_{2}-$ $\mathrm{Na}_{2} \mathrm{O}-\mathrm{B}_{2} \mathrm{O}_{3}$ glass was found to exhibit foaming behavior induced from water vaporization during the re-heating treatment. ${ }^{\text {7) }}$

Therefore, the feasibility of using hydrothermally treated BF slag and waste glass for lubricant materials in the high strain rolling process was investigated in the present work. The BF slag and glass were hydrothermally treated at $623 \mathrm{~K}$ 
and $523 \mathrm{~K}$, respectively, and their water release behaviors in the re-heating process were investigated. The glass composition chosen was the $\mathrm{SiO}_{2}-\mathrm{Na}_{2} \mathrm{O}-\mathrm{B}_{2} \mathrm{O}_{3}$ system, for which the lowest glass transition temperature and largest water dissolution were observed in the previous study during an investigation on the hydrothermal treatment of sodium-silicate based glass. ${ }^{5)}$ Furthermore, friction tests were conducted on the hydrothermally treated materials at $373-1173 \mathrm{~K}$ to understand the lubricating effects of the prepared samples.

\section{Experimental}

\subsection{Hydrothermal Treatment of BF Slag and Glass}

The composition of the water-cooled $\mathrm{BF}$ slag used is summarized in Table 1. $\mathrm{SiO}_{2}-\mathrm{Na}_{2} \mathrm{O}-\mathrm{B}_{2} \mathrm{O}_{3}$ glass was prepared from reagent grade quartz, $\mathrm{Na}_{2} \mathrm{CO}_{3}$ and $\mathrm{H}_{3} \mathrm{BO}_{3}$. Forty grams of mixture of these powders corresponding to a composition of 63 mass $\% \mathrm{SiO}_{2}-27$ mass $\% \mathrm{Na}_{2} \mathrm{O}-10 \mathrm{mass} \% \mathrm{~B}_{2} \mathrm{O}_{3}$ were melted in a $\mathrm{Pt}-20 \% \mathrm{Rh}$ crucible at $1473 \mathrm{~K}$ for $3 \mathrm{~h}$, which was followed by a cooling on a copper cooling block. Both slag and glass were confirmed to be of glass structure by X-ray diffraction analysis.

$\mathrm{BF}$ slag and pre-melted $\mathrm{SiO}_{2}-\mathrm{Na}_{2} \mathrm{O}-\mathrm{B}_{2} \mathrm{O}_{3}$ glass were subjected to a hydrothermal treatment by means of a hydrothermal hot pressing (HHP) technique developed by Yamasaki et al. ${ }^{8)}$ Details of the apparatus are given in our previous work. ${ }^{7)}$ The $\mathrm{BF}$ slag and $\mathrm{SiO}_{2}-\mathrm{Na}_{2} \mathrm{O}-\mathrm{B}_{2} \mathrm{O}_{3}$ glass were ground under 63 and $125 \mu \mathrm{m}$, respectively, and were mixed with purified water in a mass ratio of $10: 4$. The mixture was charged in an HHP autoclave and pressed at $40 \mathrm{MPa}$. The BF slag was hydrothermally hot pressed at $623 \mathrm{~K}$ for $0.5-5 \mathrm{~h}$, whereas the $\mathrm{SiO}_{2}-\mathrm{Na}_{2} \mathrm{O}-\mathrm{B}_{2} \mathrm{O}_{3}$ glass was heated to $523 \mathrm{~K}$ and then immediately cooled. The obtained samples were characterized by X-ray diffraction analysis. In addition, TG-DTA analysis was carried out to understand the water releasing behaviors of the HHP-treated samples by re-heating, under the condition of a heating rate of $10 \mathrm{~K} / \mathrm{min}$ at an argon gas flowing atmosphere with a flow rate of $100 \mathrm{~mL} / \mathrm{min}$.

\subsection{Friction Test of the Prepared Lubricant}

Friction coefficients of the HHP-treated BF slag and $\mathrm{SiO}_{2}-\mathrm{Na}_{2} \mathrm{O}-\mathrm{B}_{2} \mathrm{O}_{3}$ glass prepared above were measured by a Timken extreme pressure tester at 373-1 $173 \mathrm{~K}$. The slag or glass was ground under $300 \mu \mathrm{m}$ and mixed with water and a water soluble polymer (isobutyl maleic anhydride copolymer sodium salt) to make the lubricant solution. The addition of the polymer was aimed at preventing the dispersed slag and glass particles from agglomerating in the solution.

A schematic diagram of the apparatus for the friction measurement is shown in Fig. 1, which is mainly composed of a steel bar connected to a torque measurer and a roll made of a high speed steel (HSS). The lubricant solution was blown onto the roll by an air-wiper and the temperature of the work piece was changed by induction heating of the steel bar. The friction coefficient was determined by the measured torque, according to Eq. (1).

$$
\text { Friction coefficient }=\frac{\text { torque } \times \text { roll radius }}{\text { load }} \ldots \ldots . . .(1)
$$

Table 1. Chemical composition of the water-cooled BF slag (mass\%).

\begin{tabular}{ccccccc}
\hline $\mathrm{CaO}$ & $\mathrm{SiO}_{2}$ & $\mathrm{Al}_{2} \mathrm{O}_{3}$ & $\mathrm{MgO}$ & $\mathrm{MnO}$ & $\mathrm{T} . \mathrm{Fe}$ & $\mathrm{S}$ \\
\hline 41.5 & 35.8 & 15.3 & 5.48 & 0.28 & 1.58 & 0.79 \\
\hline
\end{tabular}

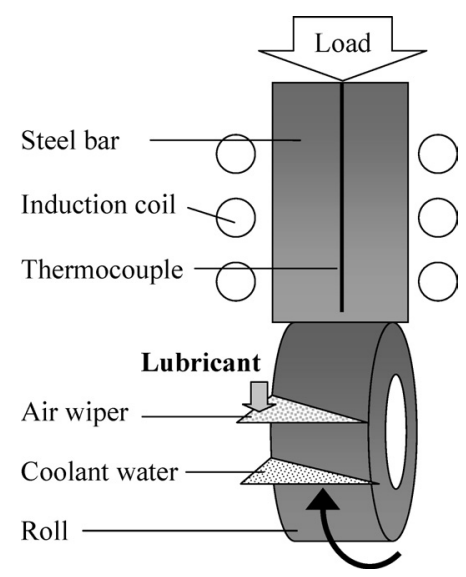

Fig. 1. Schematic sketch of an apparatus for the Timken extreme pressure tester.

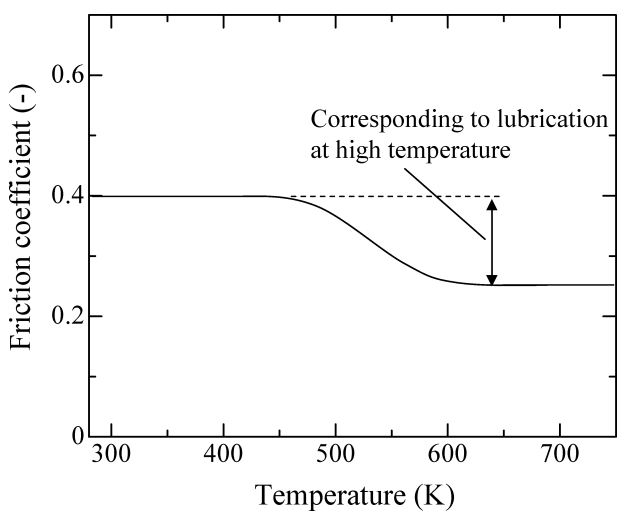

Fig. 2. Required friction property for the lubricant used in the high strain rolling for the ultrafine grained steel production.

The desirable temperature dependence of the friction coefficient suggested by Ikeda and Inagaki ${ }^{9)}$ for the high strain rolling is illustrated in Fig. 2. Sufficiently high friction is required at $373-473 \mathrm{~K}$ for stable biting between the steel and rolls whereas a decrease in friction should be provided at a high temperature of $573-673 \mathrm{~K}$ corresponding to the inside temperature of the rolls. Measurements were conducted under the condition of a rolling rate of $150 \mathrm{rpm}$ and a load of $20 \mathrm{~kg}$ at every $100 \mathrm{~K}$ from 373 to $1173 \mathrm{~K}$, and were performed 2-5 times for the same samples.

\section{Results and Discussion}

\subsection{Characterization of the Hydrothermally Treated BF Slag}

BF slag powder was well-solidified after the hydrothermal hot pressing at $623 \mathrm{~K}$. Figure 3 shows the XRD patterns for the HHP-treated BF slags with the different reaction times. Although glass was regarded as the major phase even after the hydrothermal reaction for $5 \mathrm{~h}$ from no significant difference in the hallow peak intensity in each HHP treated slag, hibschite (calcium aluminum hydroxide sili- 


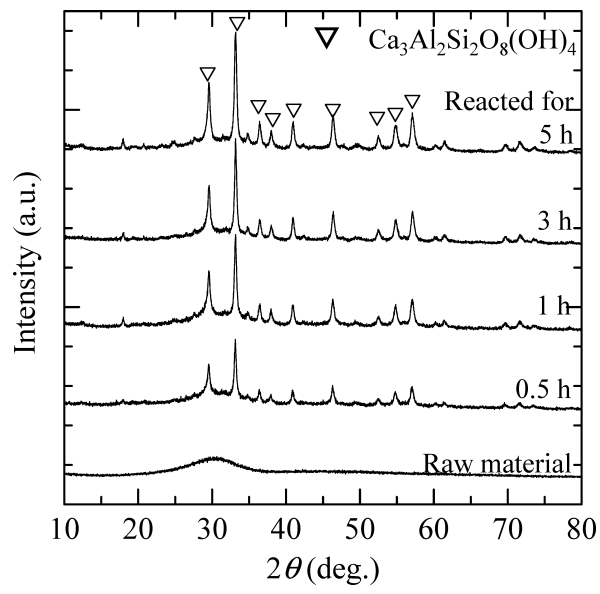

Fig. 3. XRD patterns of HHP-treated BF slag at $623 \mathrm{~K}$.

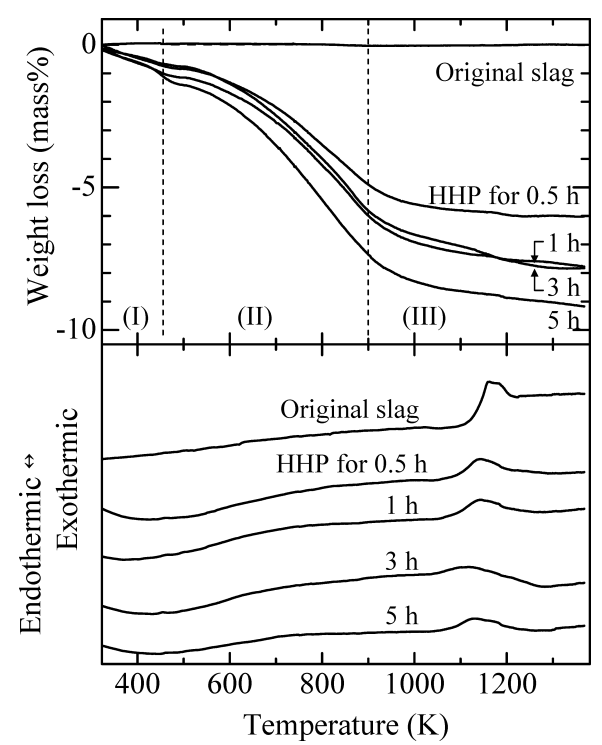

Fig. 4. TG-DTA profiles for the HHP-treated BF slag at $623 \mathrm{~K}$.

cate; $\left.\mathrm{Ca}_{3} \mathrm{Al}_{2} \mathrm{Si}_{2} \mathrm{O}_{8}(\mathrm{OH})_{4}\right)$ was identified as the only crystalline phase from the early stage of the reaction. A notable proceeding of hibshite formation was not observed by prolonging the hydrothermal reaction.

TG-DTA results for identical slags are summarized in Fig. 4. All curves in the TG analysis exhibit decrease with heating. Here, the weight loss is taken to be caused by water release from the HHP-treated slag, because the original slag doesn't change its weight at any temperature. TG profiles can be divided into three zones: (I) a gradual decrease at low temperature until $453 \mathrm{~K}$, (II) a rapid decrease until $900 \mathrm{~K}$ and (III) a gradual decrease above $900 \mathrm{~K}$. Weight loss at zone (I) may be due to the surface absorbed water. In order to know the phase releasing water at higher temperature, the HHP-treated slag prepared under the condition of holding for $1 \mathrm{~h}$ at $623 \mathrm{~K}$ was re-heated at 673-1 $173 \mathrm{~K}$ for $10 \mathrm{~min}$ in air. The results for XRD analysis of the re-heated slags are shown in Fig. 5. Below 873 K, the existing phases do not change apparently from the as-prepared HHP treated slag. The phase releasing water at the temperature range may be the hydrated glass phase formed after water dissolution into slag particles. ${ }^{10)}$ Above $973 \mathrm{~K}$, hibschite starts to decompose and gehlenite (calcium aluminum silicate; $\mathrm{Ca}_{2} \mathrm{Al}\left(\mathrm{AlSiO}_{7}\right)$ ) is found to be formed. At

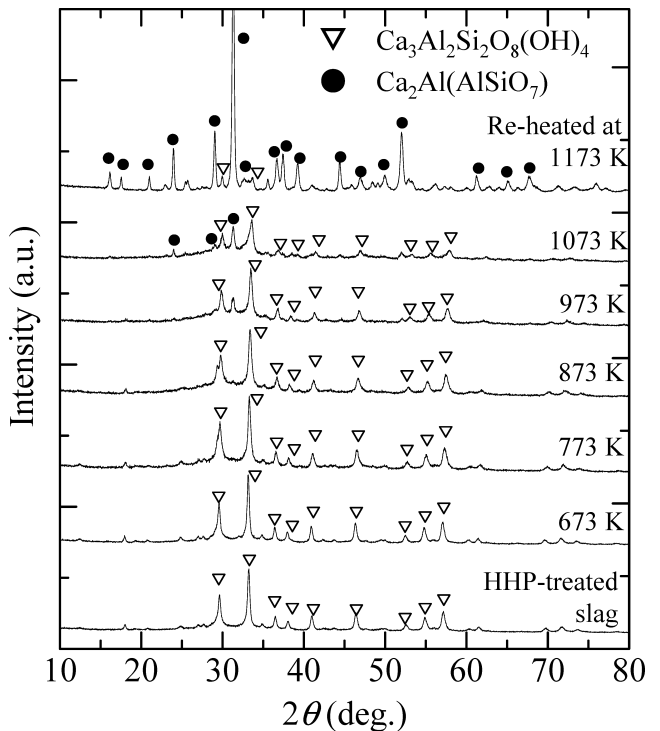

Fig. 5. XRD patterns of the HHP-treated BF slag after re-heating. HHP treatment was operated at $623 \mathrm{~K}$ for $1 \mathrm{~h}$.

$1173 \mathrm{~K}$, the crystallization of glass matrix proceeds and major phase becomes to be gehlenite. Hence, the water release at zone (II) and (III) is due to dissolved water in the hydrated glass phase and the structured water in hibschite, respectively. Concerning the effect of the reaction time on water absorption by the BF slag during the HHP treatment, it can be observed that water was absorbed as much as 6 mass\% within half an hour and its absorption rate decreased with longer reaction time. In addition, its increase is mostly observed in zone (II) in Fig. 4, indicating that the proceeding of the hydrothermal reaction of the BF slag would lead the growth of the hydrated glass phase within the reaction time in the present work. This speculation is supported by our previous work, ${ }^{10)}$ where the growth of the hydrated glass layer was observed at the surface of the synthesized slag substrate prepared in the $\mathrm{CaO}-\mathrm{SiO}_{2}-\mathrm{Al}_{2} \mathrm{O}_{3}$ system during the hydrothermal process. Regarding the DTA curves, the original slag shows the only exothermic peak around $1180 \mathrm{~K}$ corresponding to glass crystallization. Compared with the original slag, shallow and wide endothermic tendencies centered on $500 \mathrm{~K}$ are observed in the HHP-treated slags, and are considered to correspond to the beginning of water vaporization from the hydrated glass phase. Exothermic peaks above $1100 \mathrm{~K}$ correspond to glass crystallization and are shifted to lower temperatures than that of the original slag.

As a weight loss was observed in TG-DTA analysis, the HHP-treated slag was supposed to change its microstructure by the heat treatment. The HHP-treated slag re-heated at $673 \mathrm{~K}$ in Fig. 5 was subjected to SEM observation. Microstructures of the HHP-treated slag and the sample after re-heating are shown in Fig. 6. The structure of the HHPtreated sample was composed of original BF slag particles and the hydrothermally reacted phases that connect the slag particles. On the other hand, the hydrothermally reacted phase changed to a porous structure composed of submicron-sized particles after re-heating. Since it was confirmed that hibschite does not decompose at the firing temperature by XRD measurement, the phase releasing water and changing its structure with the heat treatment at $673 \mathrm{~K}$ cor- 
(a)

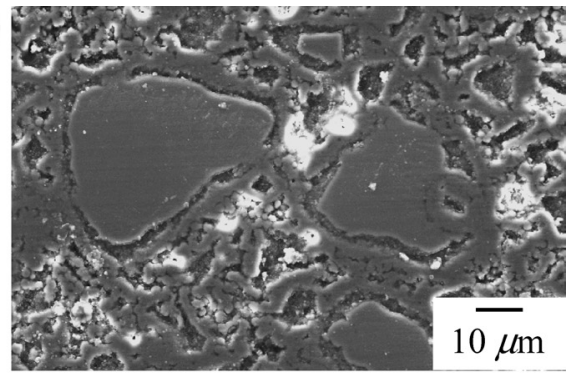

(b)

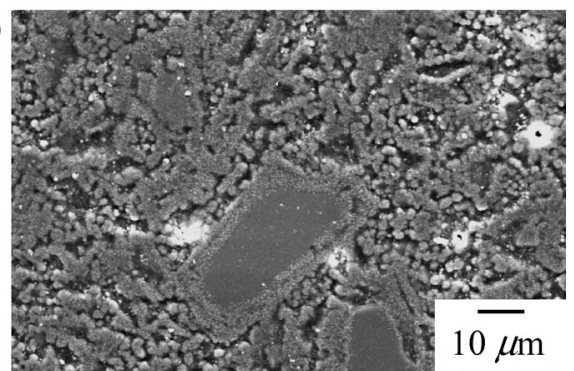

(c)

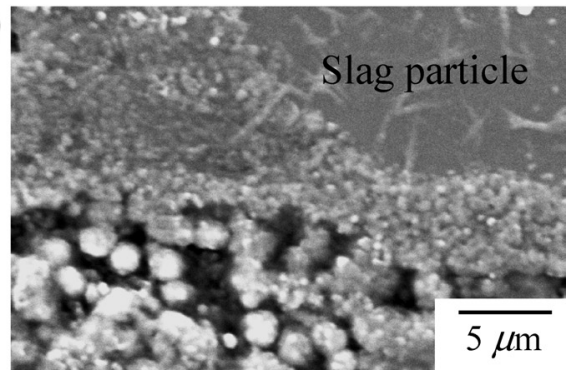

Fig. 6. SEM images of microstructure of (a) the HHP-treated slag and (b), (c) the slag after heating at $673 \mathrm{~K}$ for $10 \mathrm{~min}$.

responds to the hydrated glass phase. Accordingly, it can be expected that when the HHP-treated BF slag is applied to the lubricant in the high strain rolling, it will be crushed under the rolling load due to its change to a brittle structure with heating and will provide a lower friction than that at the charging temperature.

\subsection{Characterization of the Hydrothermally Treated $\mathrm{SiO}_{2}-\mathrm{Na}_{2} \mathrm{O}-\mathrm{B}_{2} \mathrm{O}_{3}$ Glass}

A dense compact was obtained by the HHP treatment of the 63 mass $\% \mathrm{SiO}_{2}-27$ mass $\% \mathrm{Na}_{2} \mathrm{O}-10$ mass $\% \mathrm{~B}_{2} \mathrm{O}_{3}$ glass powder at $523 \mathrm{~K}$. It contained 8 mass $\%$ water and was composed of original glass particles and intragrain hydrated glass, of which details on the structural analysis are given in the literature. ${ }^{7)}$ In order to know the morphological change of the hydrothermally treated $\mathrm{SiO}_{2}-\mathrm{Na}_{2} \mathrm{O}-\mathrm{B}_{2} \mathrm{O}_{3}$ glass, a piece of the compact was heated at $673 \mathrm{~K}$ for $10 \mathrm{~min}$ in air. Figure 7 shows the change in its shape before and after firing. A remarkable macroscopic expansion attributed to its foaming behavior was observed and its weight was reduced by 8 mass $\%$. A porous glass material with an apparent density of about $0.4 \mathrm{~g} / \mathrm{cm}^{3}$ was obtained. This foaming of the hydrothermally treated glass was observed at as low as $473 \mathrm{~K}$ and was clarified to be due to its softening and water vaporization in the previous work. $\left.{ }^{7}\right)$ Hence, the use of HHP-treated glass as a lubricant in high strain rolling was considered to be promising, taking into account its morphological change and softening behavior with heating above $473 \mathrm{~K}$.
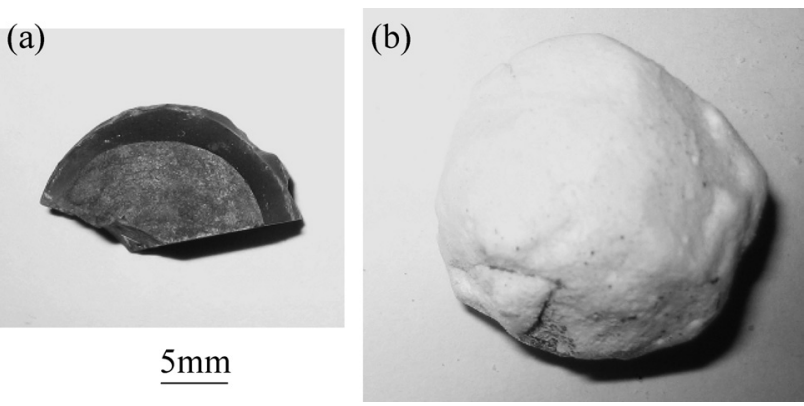

Fig. 7. HHP-treated 63 mass $\% \mathrm{SiO}_{2}-27$ mass $\% \mathrm{Na}_{2} \mathrm{O}-10$ mass $\% \mathrm{~B}_{2} \mathrm{O}_{3}$ glass, (a) before, (b) after the heat treatment at $673 \mathrm{~K}$ for $10 \mathrm{~min}$ in air atmosphere.

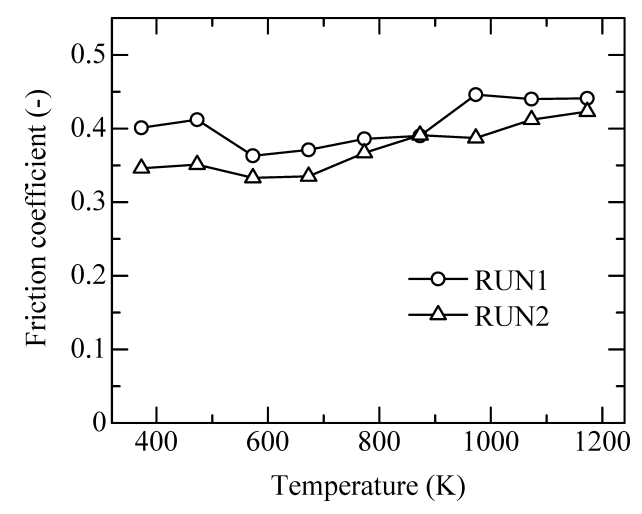

Fig. 8. Friction coefficient measured by the Timken extreme pressure tester with water sprayed to the rolls.

\subsection{Friction Properties of the HHP-treated BF Slag and $\mathrm{SiO}_{2}-\mathrm{Na}_{2} \mathrm{O}-\mathrm{B}_{2} \mathrm{O}_{3}$ Glass}

The friction behavior in using only pure water as a lubricant measured by the Timken extreme pressure tester is shown in Fig. 8. The friction coefficient exhibited an increasing tendency as the temperature increased. This can be explained by the large friction induced from the thermal expansion of both a steel bar and a roll, and suggests a difficulty in obtaining lubricity with only liquid solutions.

HHP-treated BF slags were mixed with water and a water soluble polymer in a mass ratio of slag: water: polymer of $1: 4: 5$ and $1: 1: 1$, and subjected to the friction test. Here, the slags were prepared under a hydrothermal condition of holding at $623 \mathrm{~K}$ for 1 and $5 \mathrm{~h}$ to determine the effect of the water content of the slag on the friction property. Measured friction coefficients are summarized in Fig. 9. Although there appears to be a scattering of measured values, the friction coefficient shows a decreasing tendency over $673 \mathrm{~K}$ for each sample. This is considered to be caused from the microstructure change of the HHP-treated slag by heating as shown in Fig. 5 induced by the absorbed water after the hydrothermal treatment. Enlargement of the slag fraction in the lubricant solution brought a slight improvement in the lubricity at higher temperature, which can be regarded as being the result of a larger shrinkage of the solid particles at high temperature in the lubricant solution of the large slag ratio. On the other hand, the reaction time during the HHP treatment on the BF slag did not affect the friction tendency of the lubricant. It is often said that the strength of the productive material after the hydrothermal solidification is controlled by the formed crystal that connects the origi- 

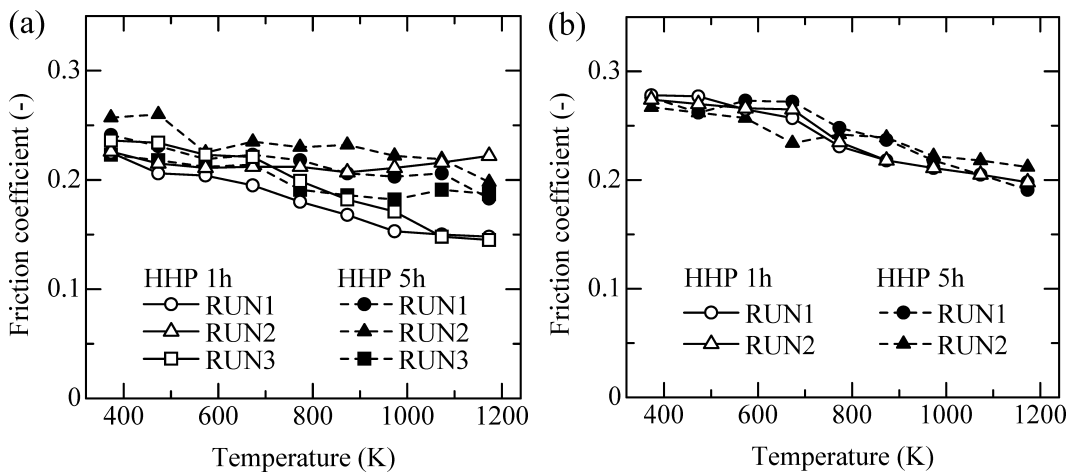

Fig. 9. Friction coefficient measured by the Timken extreme pressure tester with the lubricant containing BF slag after the hydrothermal hot pressing at $623 \mathrm{~K}$ for 1 and $5 \mathrm{~h}$. Mixing ratio in the lubricant, slag: water:polymer (a) $1: 4: 5$ and (b) $1: 1: 1$.
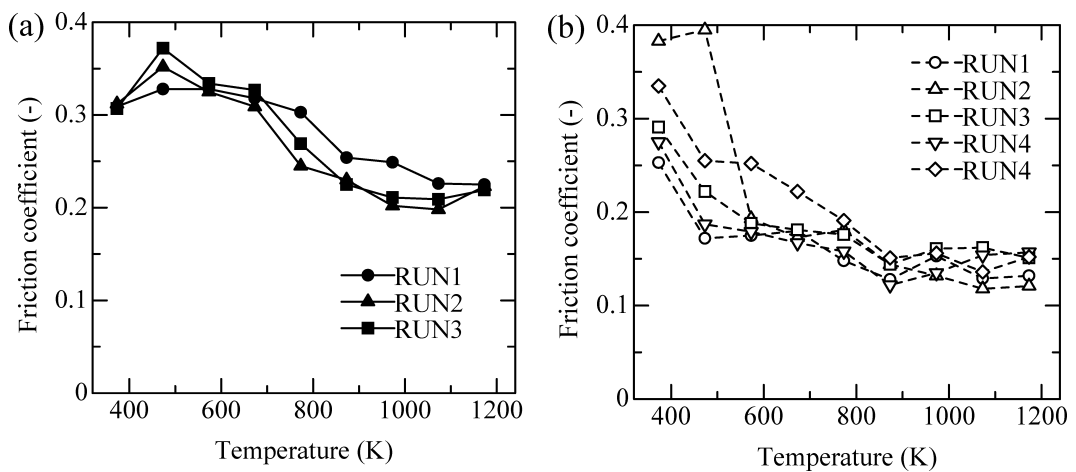

Fig. 10. Friction coefficient measured by the Timken extreme pressure tester with the lubricant containing the 63 mass $\% \mathrm{SiO}_{2}-27$ mass $\% \mathrm{Na}_{2} \mathrm{O}-10$ mass $\% \mathrm{~B}_{2} \mathrm{O}_{3}$ glass. (a) original glass (b) glass after hydrothermal hot pressing at $523 \mathrm{~K}$.

nal particles. No remarkable difference in the formation of hibschite, the only crystal after the hydrothermal treatment, was observed between the reactions of 1 and $5 \mathrm{~h}$. Assuming that the strength of the HHP-treated slag is controlled by hibschite, it can be considered to be comparable in the two slags and not to affect the friction coefficient in the measurement. From the lubricating tendency above $673 \mathrm{~K}$, there exists the possibility for using the HHP-treated slag as a lubricant in the high strain rolling process.

The friction tendency of the HHP-treated glass, and also the original $\mathrm{SiO}_{2}-\mathrm{Na}_{2} \mathrm{O}-\mathrm{B}_{2} \mathrm{O}_{3}$ glass for comparison, were studied with the Timken extreme pressure tester. Figure 10 shows the results for friction tests of the two materials, where the mixing ratio was fixed to be glass: water: polymer, $1: 4: 5$. It can be observed that the friction coefficient of the lubricant with the original $\mathrm{SiO}_{2}-\mathrm{Na}_{2} \mathrm{O}-\mathrm{B}_{2} \mathrm{O}_{3}$ glass (Fig. 10(a)) began to decrease at $773 \mathrm{~K}$. This might be attributed to the softening behavior above the glass transition temperature, which can be supposed to be around $720 \mathrm{~K}$ from the approximation by Kauzmann ${ }^{11)}$ who suggested that the glass transition temperature can be estimated to be two-thirds of the melting temperature. The liquidus temperature of the above glass is estimated to be $1073 \mathrm{~K}$ from the $\mathrm{SiO}_{2}-\mathrm{Na}_{2} \mathrm{O}-\mathrm{B}_{2} \mathrm{O}_{3}$ ternary phase diagram. ${ }^{12)}$ On the other hand, the friction coefficient of the HHP-treated glass as shown in Fig. 10(b) exhibits a rapid decrease in the friction coefficient at $473 \mathrm{~K}$, which keeps decreasing as the temperature increases. This lubrication can be considered to be caused by the water release and macroscopic structural change of the HHP-treated glass described in Sec. 3.2.
Hence, the hydrothermal treatment on $\mathrm{SiO}_{2}-\mathrm{Na}_{2} \mathrm{O}-\mathrm{B}_{2} \mathrm{O}_{3}$ glass brings its softening at lower temperature, and the hydrothermally treated glass was found to be a promising material for the lubricant from the strong lubricating behavior above $473 \mathrm{~K}$.

\section{Conclusions}

The possibility was investigated of applying BF slag and waste glass as lubricants in the high strain rolling process for producing ultrafine-grained steels. Water introduction into both materials was carried out through hydrothermal treatment, as the water release from the prepared materials is expected to bring a structural change in the hot rolls, leading to a lubricating effect.

Water-cooled $\mathrm{BF}$ slag and $63 \mathrm{mass} \% \mathrm{SiO}_{2}-27 \mathrm{mass} \%$ $\mathrm{Na}_{2} \mathrm{O}-10$ mass $\% \mathrm{~B}_{2} \mathrm{O}_{3}$ glass were hydrothermally treated by means of a hydrothermal hot pressing method and their water releasing behaviors with re-heating were investigated. In addition, friction properties of the synthesized lubricants containing the hydrothermally treated materials were measured by a Timken extreme pressure tester at 373-1 $173 \mathrm{~K}$. The results obtained are listed below.

(1) When BF slag was hydrothermally treated at $623 \mathrm{~K}$ for $0.5-5 \mathrm{~h}$, it solidified and absorbed water at a content of 6-8 mass \%. With heating at $673 \mathrm{~K}$ for $10 \mathrm{~min}$, the HHPtreated slag released water and changed its microstructure to be locally porous at the hydrothermally reacted phase.

(2) Hydrothermally treated 63 mass $\% \mathrm{SiO}_{2}-27 \mathrm{mass} \%$ $\mathrm{Na}_{2} \mathrm{O}-10$ mass $\% \mathrm{~B}_{2} \mathrm{O}_{3}$ glass at $523 \mathrm{~K}$ contained 8 mass $\%$ 
water and released water above $473 \mathrm{~K}$. Furthermore, it exhibited foaming behavior with heating and changed to be porous glass.

(3) Friction properties of lubricants prepared by mixing the HHP-treated BF slag and $\mathrm{SiO}_{2}-\mathrm{Na}_{2} \mathrm{O}-\mathrm{B}_{2} \mathrm{O}_{3}$ glass with water and a water-soluble polymer were measured. A lubricating tendency was observed above $673 \mathrm{~K}$ in the lubricant containing HHP-treated BF slag. Further lubricity was obtained with the HHP-treated glass over $473 \mathrm{~K}$. Hence, the hydrothermally treated glass was found to be a promising material for the lubricant in the high strain rolling process.

\section{Acknowledgement}

The present research is partly supported by Priority Assistance for the Formation of Worldwide Renowned Centers of Research-The Global COE Program (project: Center of Excellence for Advanced Structural and Functional Materials Design) from the Ministry of Education, Culture, Sports, Science and Technology (MEXT), Japan.

\section{REFERENCES}

1) http://slg.jp/tokei/japan/18/index2.htm., (Sept. 1, 2007).

2) T. Hashida: Final report of Research Group Activity on Application of Slag to Construction Materials for Urban Infrastructure, ISIJ, (2004), 24.

3) Z. Matamoros-Veloza, K. Yanagisawa and N. Yamazaki: J. Mater. Sci. Lett., 18 (1999), 1811.

4) T. Hosoda and T. Kawamura: Bull. Iron Steel Inst. Jpn., 4 (1999), 748.

5) M. Kiuchi: Proc. of the 1st Symp. on PROTEUS Project, NEDO, Tokyo, Japan, (2004), 1.

6) M. Nakamoto, J. Lee, T. Tanaka, J. Ikeda and S. Inagaki: ISIJ Int., 45 (2005), 1567.

7) T. Yoshikawa, S. Sato and T. Tanaka: ISIJ Int., 48 (2008), 123.

8) N. Yamazaki, K. Yanagisawa, M. Nishioka and S. Kanahara: $J$. Mater. Sci. Lett., 5 (1986), 355.

9) J. Ikeda and S. Inagaki: Proc. of the 1st Symp. on PROTEUS Project, NEDO, Tokyo, Japan, (2004), 21.

10) T. Yoshikawa, M. Hosokawa and T. Tanaka: submitted to ISIJ Int.

11) W. Kauzmann: Chem. Rev., 43 (1948), 219.

12) E. M. Levin, C. R. Robbins and H. F. McMurdie: Phase Diagrams for Ceramists, The American Ceramic Society, Ohio, (1964), 184. 